Discussion Paper No. 08-070

\title{
Grade Inflation, Social Background, and Labour Market Matching
}

Robert Schwager

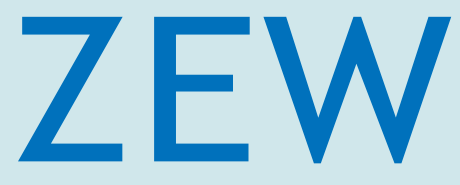

Zentrum für Europäische Wirtschaftsforschung $\mathrm{GmbH}$

Centre for European

Economic Research 
Discussion Paper No. 08-070

\section{Grade Inflation, Social Background, and Labour Market Matching}

Robert Schwager

Download this ZEW Discussion Paper from our ftp server:

ftp://ftp.zew.de/pub/zew-docs/dp/dp08070.pdf

Die Discussion Papers dienen einer möglichst schnellen Verbreitung von neueren Forschungsarbeiten des ZEW. Die Beiträge liegen in alleiniger Verantwortung der Autoren und stellen nicht notwendigerweise die Meinung des ZEW dar.

Discussion Papers are intended to make results of ZEW research promptly available to other economists in order to encourage discussion and suggestions for revisions. The authors are solely responsible for the contents which do not necessarily represent the opinion of the ZEW. 


\section{Non-Technical Summary}

The results a student obtains in examinations at the end of school to a large extent determine her future labour market or academic career. Because of this importance, and since students from disadvantaged ethnical or social backgrounds typically fare worse in formal tests of academic achievement, some observers argue against tough testing and grading policies so as not to expose the disadvantage of such students to employers and/or further education institutions.

Addressing this debate, the present paper examines the relationship between grades, social origin, and the labour market. It provides a game theoretic model describing the matching of workers of different abilities to different jobs. The role of grades in this context is to inform employers about the ability of workers. The paper shows that, if grades honestly reveal abilities, in equilibrium the most able workers are matched to the most demanding jobs. Moreover, compared to applicants with a mediocre grade, applicants with a good grade obtain a wage premium which reflects the productivity differential and the relative scarcity of workers with differering abilities. If, however, the school inflates grades by awarding good grades to some low ability students, then the matching of jobs and workers is not only determined by ability but also by social background: The best jobs are then reserved to highly graded students originating from the upper social classes. In addition, these students are paid an additional wage premium which students from lower social classes with a good grade do not obtain. These results arise from the fact that grade inflation reduces the informational content of grades, thereby inducing employers to use an unfavourable background as an additional signal for low ability.

In further results, it is examined how this effect determines the preferences for grading policies in the student population. It is shown that the aggregate wage sum received by workers from the disadvantaged social class strictly decreases if grades are inflated. Moreover, high ability students from the favoured social origin, whom one might call the "elite", may indeed prefer grade inflation to honest grading. This may be worthwhile since with inflated grades, able students from disadvantaged backgrounds cannot signal their ability anymore, and so can compete less successfully for the most attractive jobs, leaving more of those for 
the students from favoured backgrounds.

For education policy, these results suggest that lenient standards in schools are not a suitable instrument for promoting upward social mobility. Quite the contrary, a strictly meritocratic schooling system which administers tough tests and grades poor performance honestly might be the best way to promote the prospects of able, aspiring students from disadvantaged backgrounds. 


\section{Zusammenfassung}

Schulnoten entscheiden über die Verteilung von beruflichen Chancen. Dies ist besonders für Schüler aus sozial schwachen Familien bedeutsam, da sie bei Leistungstests typischerweise schlechter abschneiden als der Durchschnitt. Aus diesem Grund wird gelegentlich eine Absenkung von Prüfungsstandards gefordert, um so der mit schlechten Noten oder einem Schulabbruch verbundenen Stigmatisierung zu begegnen. Auf der anderen Seite wird oftmals beklagt, dass gute Noten und akademische Abschlüsse heute zu leicht erreichbar sind, dass also Noten im Laufe der Zeit gleichsam "inflationiert" worden sind.

In diesem Spannungsfeld untersucht der vorliegende Beitrag den Zusammenhang von Noten, sozialer Herkunft und dem Arbeitsmarkt. Dazu wird ein spieltheoretisches Modell präsentiert, das die Zuordnung von Arbeitskräften mit verschiedenen Fähigkeiten auf unterschiedlich anspruchsvolle Arbeitsplätze abbildet. Auf diesem Markt haben Noten die Funktion, die Arbeitgeber über den Leistungsstand der Bewerber zu informieren. Wenn Noten die Fähigkeiten wahrheitsgemäß widergeben, dann werden die anspruchsvollsten Arbeitsplätze mit den besten Arbeitskräften besetzt. Wenn Noten dagegen in dem Sinne inflationiert werden, dass auch einige weniger fähige Absolventen gute Noten erhalten, dann sind die attraktivsten Arbeitsplätze denjenigen Absolventen vorbehalten, die nicht nur über eine gute Note, sondern auch über eine privilegierte Herkunft verfügen. Diese Arbeitskräfte erhalten zudem einen höheren Lohn als die Arbeitnehmer aus sozial schwachen Schichten, auch wenn diese dieselbe gute Note erzielt haben. Diese Ergebnisse beruhen darauf, dass Noteninflation den Informationsgehalt der Noten verringert und Arbeitgeber deshalb die soziale Herkunft als weiteres, informatives Signal nutzen, um die Fähigkeiten der Bewerber einzuschätzen.

Auf Grund dieses Wirkungszusammenhangs nimmt die an Arbeitskräfte aus benachteiligten Schichten fließende Lohnsumme mit zunehmender Noteninflation ab. Darüber hinaus ist es möglich, dass fähige Schüler aus gehobenen Schichten, die "Elite", Noteninflation gegenüber einer wahrheitsgemäßen Benotung bevorzugen. Eine solche Notenvergabe macht es nämlich guten Schülern aus sozial schwachen Verhältnissen unmöglich, ihre Fähigkeiten auf dem Arbeitsmarkt zu signalisieren, so dass sie nicht mehr mit den Schülern aus gehobenen Schichten 
um die begehrtesten Arbeitsplätze konkurrieren können.

Aus bildungspolitischer Sicht bedeuten diese Ergebnisse, dass nachsichtige Benotung und reduzierte Prüfungsanforderungen nicht geeignet sind, um gesellschaftliche Mobilität zu fördern. Im Gegenteil, fähige, aufstrebende Schüler aus schwierigem sozialem Umfeld haben in einem meritokratischen Schulsystem, das Leistungen ernsthaft prüft und die erzielten Ergebnisse ungeschönt dokumentiert, die besten Chancen. 


\title{
Grade Inflation, Social Background,
}

\author{
AND \\ LABOUR MARKET MATCHING ${ }^{\mathrm{a}}$
}

\author{
Robert Schwager \\ Georg-August-Universität Göttingen ${ }^{\mathrm{b}}$ \\ and Zentrum für Europäische Wirtschaftsforschung, Mannheim
}

First version: March 17th, 2008.
This version: August 18th, 2008.

\begin{abstract}
A model is presented where workers of differing abilities and from different social backgrounds are assigned to jobs based on grades received at school. It is examined how this matching is affected if good grades are granted to some low ability students. Such grade inflation is shown to reduce the aggregate wage of the lower class workers because employers use social origin as a signal for productivity if grades are less than fully informative. Moreover, the high-ability students from the higher class may benefit from grade inflation since this shields them from the competition on the part of able students from the lower classes.
\end{abstract}

Keywords: education, grading, standards, assignment, social mobility JEL: I21, J24, C78

\footnotetext{
${ }^{\text {a} P a r t ~ o f ~ t h i s ~ r e s e a r c h ~ w a s ~ d o n e ~ w h i l e ~ t h e ~ a u t h o r ~ w a s ~ v i s i t i n g ~ t h e ~ I n s t i t u t e ~ f o r ~ F e d e r a l i s m ~ a n d ~}$ Intergovernmental Relations at the University of Kentucky. I am grateful for the hospitality I experienced there. Financial support received from IFIR and the Deutsche Forschungsgemeinschaft, in the priority programme 1142 "Institutional Design of Federal Systems", is thankfully acknowledged. I am indebted to participants of the Public Economics Seminar HannoverPaderborn-Göttingen, 2007, the launch conference of the Center for Vocational Education and Training, Paderborn, 2008, the Applied Microeconomics and Organisations Seminar at University of Frankfurt, and the Workshop of the DFG priority programme 1142 "Institutional Design of Federal Systems", Dresden, 2008, for helpful discussions. All remaing errors are my own.

bphone: +49/551/397244, email: rschwag@uni-goettingen.de
} 


\section{Introduction}

For many students, examinations are the most important aspect of schooling, and many of them feel substantial pressure to improve the grades they obtain in such examinations. This attitude is most pronounced when examination results have immediate and important consequences for the student such as failure to graduate from high school, as is the case under the policy of "high stakes testing" in many U.S. states. Because of this impact on students' well-being, some observers have reservations about tough examination and grading standards. For example, the California Teachers Association suggests to complement the current California High School Exit Exam by "parallel forms of assessment" such as "essays and personal communications" (see California Teachers Association, 2006). This should allow to reduce the rate of students failing in the assessment which is considered to be excessive. Similarly, the union of German teachers $G E W$ demands abolishing quantitative grades for young pupils on the grounds that they discourage students (see Gewerkschaft Erziehung und Wissenschaft, 2006). In addition to the general impact of tough standards on all students, it is specifically feared that students from disadvantaged backgrounds are hurt disproportionately by tough examination standards. This concern is rooted in the fact that, on average, students from poor, minority, or immigrant families perform less well in tests (see Madaus and Clarke, 2001). As a consequence, one might think that softening the grading scheme or lowering graduation standards will improve the opportunities of these students. While these considerations suggest that examination standards are too tough, the opposite view is also expressed. Proponents of this view complain that good grades are awarded too easily so that employers and further education institutions cannot count on the qualification of a candidate with a good grade. Specifically, there seems to be widespread belief that such a practice, which is labelled "grade inflation", occurs routinely at the university level, even at the most prestigious institutions (see for example Mansfield, 2001, and Spiegel online, 2007).

Addressing this debate, the present paper examines the relationship between grades, social origin, and the labour market. It serves two purposes. First, on a rather fundamental level, a model is presented which allows to analyse in a 
natural way the role of grades for the allocation on the labour market. This model is a continuous version of the two-sided matching model introduced by Roth and Sotomayor (1990), and later used, for example, by Cole, Mailath, and Postlewaite (1992), Corneo and Grüner (2000), and Clark and Kanbur (2004) in the context of social interaction. Following these contributions, the concept of a stable assignment is used to describe the allocation on the labour market. In a stable assignment, the matching between firms and workers and the resulting payoffs are such that no agent strictly prefers to stay alone, and such that no pair consisting of a firm and a worker can improve on their payoffs by matching together.

In the model presented here, there are workers of high and low ability. The central feature of the model is that workers with high ability, while being more productive than low-ability workers on every job, have a comparative advantage on the most demanding jobs. Thus, the labour market should match the most able workers with the most productive jobs and allocate the less demanding jobs to workers with lower ability. In such a context, grades serve an obvious information function by signalling ability to firms. To reflect the concern about the informational content of grades mentioned above, a very simple form of grade inflation is introduced which consists of awarding a good grade (an " $A$ ") to a fraction of low ability students. The matching of workers to firms and the resulting wages in a stable assignment are characterised as a function of the extent of grade inflation. It is shown that the wage premium earned by students with an $A$ relative to those who carry the lower grade $B$ is eroded by grade inflation. While this effect hurts able students, grade inflation allows low ability students to grasp this "grade premium" with a certain probability, and so is beneficial for these students.

The second central theme of the paper is the impact of grade inflation on the job prospects of socially disadvantaged students. To analyse this issue, students are modelled to belong to two social classes, with the share of high ability students being higher in the favoured class. This assumption reflects the stylised fact, well documented by many empirical studies (see, for example, Ermisch and Francesconi, 2001, Blanden and Gregg, 2004, and Wössmann, 2008), that students' performance and academic achievement are strongly influenced by family 
background. It is worth noting that it is not relevant for the present analysis whether this fact is due to a biased school system, insufficient resources, inadequate parenting, inherited genetic endowments, or any other cause (for an empirical analysis of economic vs. natural causes of scholarly achievement, see Plug and Vijverberg, 2003). Rather, the paper takes abilities as they occur at the time of the examination as given. Addressing the concern, mentioned above, that lower class students, on average, fare worse in tests at this age, the paper then asks whether such students benefit from reducing the information content of grades. This is not the case, however, as long as social origin is observable. Indeed, it is shown that the aggregate wage received by lower class workers is strictly decreasing in the extent of grade inflation. The reason is that, when grades do not fully reveal true abilities, employers use social origin as an additional source of information to update their beliefs about the expected productivity of a potential worker. With grade inflation, employers therefore discount the value of grade $A$ earned by a lower-class student relative to the same grade earned by a higher-class student. Put differently, grade inflation induces firms to statistically discriminate against applicants from disfavoured origins.

The analysis shows that in a stable assignment, this effect results in a second wage premium, the "social premium", which is paid to $A$-students from the favourable social origin but not to lower-class $A$-students. In further results, it is examined how the grade premium and the social premium together determine the preferences for grading policies in the student population, and possible voting outcomes are discussed. Specifically, it is shown that high ability students from the favoured social origin, whom one might call the "elite", may indeed prefer grade inflation so as to secure the social premium. This may be worthwhile since with inflated grades, able students from disadvantaged backgrounds cannot signal their ability anymore, and so can compete less successfully for the most attractive jobs, leaving more of those for the students from favoured backgrounds.

By addressing the link between degrees and the labour market, the paper contributes both to labour economics and to the economics of education. In labour economics, it has long been recognised that the assignment of workers to tasks affects wages (see the survey by Sattinger, 1993). For example, Teulings (1995) and Costrell and Loury (2004) provide general equilibrium models where, similar 
to the approach used here, high-ability workers have a comparative advantage in performing demanding jobs. As a main feature of assignment models, which the present paper shares, these contributions show that the wage differential obtained by high-ability workers does not only reflect productivity differences on any given job but depends on the matching between workers and tasks. Moreover, the assignment and the wages are affected by the information employers have about workers of different types. If such information is incomplete, by consequence, statistical discrimination affects the labour market outcome (see, for example, Coate and Loury, 1993, Norman, 2003, and Bjerk, 2008), just as in the present paper. To this literature, the present paper adds by highlighting the importance of school leaving grades and social origin for the matching and the wages obtained in equilibrium. It shows that different subgroups of the population are differently affected by the statistical discrimination introduced by grade inflation, thereby changing political preferences concerning the grading scheme to be employed. The paper so points out that the equilibrium assignment on the labour market may feed back into the schooling system.

An issue which raises concerns similar to those expressed about tough school leaving examinations are formal tests of job applicants administered by the employer. In an empirical study of the hiring decisions of a large retailing firm, Autor and Scarborough (2008) provide an analysis of the effects of such tests. They show that in this firm, as one might have expected, minority applicants fare worse than average in formal tests. However, introducing such tests did not decrease the chances of members of these groups to be hired. This result is due to an effect similar to the one analysed in the present paper: Like truthful grading, the formal test provides valuable information about the abilities of individuals and so reduces the scope for statistical discrimination against minority applicants. Thus, the result by Autor and Scarborough (2008) lends some empirical support for the theory laid out here. Its conceptual framework, however, is rather different, and arguably somewhat narrower, than the model presented here. In describing only the selection of workers for one type of job, these authors do not address the issue of assigning different workers to different tasks which is central to the present contribution. Moreover, contrary to Autor and Scarborough who focus on a single firm, the present approach endogenises wages in an equilibrium framework and so can explain wage differentials across grades and social origins. 
In the theoretical research on education, grading policies so far have received rather little attention. In several classical contributions, Betts (1998a) and Costrell $(1994,1997)$ develop a model where grades are used to provide incentives for students so as to exert effort at school. This model has been extended by Himmler and Schwager (2007) who show that the social composition of a school determines its grading policy. In Jürges, Richter, and Schneider (2005), the role of testing is to provide incentives for teachers rather than for students. Finally, Chan, Hao, and Suen (2007) provide a signalling model where grade inflation affects the assignment of workers to tasks, and where grade inflation occurs in equilibrium as a result of cheap talk. To this model, the present paper adds a game theoretic foundation of the equilibrium assignment on the labour market. Moreover, both papers differ with regard to the information structure used. While Chan, Hao, and Suen (2007) focus on the asymmetric information between schools and firms regarding the grading scheme, in the present paper, the interaction of grades and social origin as signals of ability is at the centre of the analysis. Altogether, the specific contribution to education economics offered by the the present paper consists in clarifying the role of grades and social origin for the allocation on the labour market.

The paper is organised in the usual way: The model is presented in Section 2. In the following Section 3, the stable assignment on the labour market is characterised. Section 4 contains the results on the interaction of grade inflation and the wages received by the different subgroups of workers. Section 5 summarises and offers some lines for future research. Longer proofs are collected in the Appendix.

\section{The Model}

The model describes a labour market with a continuum of firms each of which offers one job and a continuum of workers. The sets of firms and workers are modelled as adjacent intervals on the real line, with $i \in[0, M)$ denoting firms, $j \in[M, M+N)$ denoting workers, and $k \in[0, M+N)$ being used for an agent of unspecified role. The lengths $M>0$ and $N, 0<N<M$, of the intervals are the Lebesgue-measures of the sets of workers and firms. 
Workers. Workers are characterised by their skill, or ability, $s \in\{a, b\}$, with $a(b)$ denoting the higher (lower) skill level, and by their social origin, or class, $c \in\{h, \ell\}$, with $h(\ell)$ denoting that the worker comes from a socially favoured (disadvantaged) background. To refer to the ability and class of worker $j \in[M, M+N)$, I write $s(j)$ and $c(j)$. The numbers $n_{s c}>0$, for $s=a, b$ and $c=h, \ell$, denote the measures of workers with skill $s$ originating from class $c$. The measure of high- (low)- skilled workers is $n_{a}=n_{a h}+n_{a \ell}\left(n_{b}=n_{b h}+n_{b \ell}\right)$, and the measure of socially favoured (disadvantaged) workers is $n_{h}=n_{a h}+n_{b h}$ $\left(n_{\ell}=n_{a \ell}+n_{b \ell}\right)$. The population measures satisfy $n_{a h}+n_{a \ell}+n_{b h}+n_{b \ell}=N$ and

\section{Assumption $1 \quad n_{a h} / n_{h}>n_{a \ell} / n_{\ell}$.}

Assumption 1 states that, while there are individuals of both skills in both social groups, the share of high-ability workers is larger in the socially favoured group than in the disadvantaged group. In view of Assumption 1, it is apparent that social background is not the only interpretation of the variable "class". More broadly, this variable can represent any characteristic which is not itself ability, but which, in the population as a whole, is correlated with ability or performance at the workplace.

As a student, before entering the workplace, each worker is given a grade $G \in$ $\{A, B\}$, with $G(j)$ denoting the grade given to worker $j \in[M, M+N)$. The grade $A(B)$ is meant to express that the student with this grade is of high (low) ability. Grading policy is captured by the fraction $\gamma, 0 \leq \gamma \leq 1$, of students with ability $b$ who nevertheless obtain grade $A$. Thus, a positive value of $\gamma$ means that grades are inflated, while $\gamma=0$ indicates "honest" grading. This modelling choice is simplified in two respects. Firstly, the converse of grade inflation would be that some truly excellent students are awarded only grade $B$. Such "grade deflation" does not seem to be a realistic case and is so ruled out for simplicity. Secondly, the extent of grade inflation is assumed to be the same throughout the student population, irrespective of social class. This assumption captures the idea that systematic discrimination along social origins inside the classroom will be detected by students, and so can be ruled out legally. 
Combining grade and social origin, the set of workers is partitioned into four subsets. Depending on the grade inflation parameter $\gamma$, the measure of workers with grade $G$ originating from class $c$ is denoted by $N_{G c}(\gamma)$, for $G=A, B$ and $c=h, \ell$. One has

$$
\begin{aligned}
& N_{A c}(\gamma)=n_{a c}+\gamma n_{b c} \quad \text { for } c=h, \ell, \\
& N_{B c}(\gamma)=(1-\gamma) n_{b c} \quad \text { for } c=h, \ell,
\end{aligned}
$$

and the total measure of students with grade $G=A, B$ is denoted by $N_{G}=$ $N_{G h}+N_{G \ell}$.

Firms. The technology is described by two production functions $f_{s}:[0, M) \rightarrow$ $\mathbb{R}_{+}$, for $s=a, b$, which are twice continuously differentiable. The value $f_{s}(i)$ gives the aggregate output produced by the firms in the interval $[0, i)$ if all of them employ a worker of skill $s$. Correspondingly, the derivative $f_{s}^{\prime}(i)$ describes the output produced by firm $i$ if its job is taken by a worker of ability $s$. The production functions satisfy

Assumption 2 (a) $f_{s}^{\prime \prime}(i)<0$ for $s=a, b$ and for all $i \in[0, M)$,

(b) $f_{a}^{\prime}(i)>f_{b}^{\prime}(i)>0$ for all $i \in[0, M)$,

(c) $f_{a}^{\prime \prime}(i)-f_{b}^{\prime \prime}(i)<0$ for all $i \in[0, M)$.

Assumption 2 (a) states that firms are labelled in decreasing order of productivity. Such differences in productivity across firms can, for example, reflect different endowments of capital, different entrepreneurial abilities of the firms' owners, or different technologies. As expressed in Assumption 2 (b), workers of both skill levels are productive, but every firm produces more output with a high ability than with a low ability worker. Finally, Assumption 2 (c) requires that the difference in output produced by workers of both skills decreases with the index of the firm. This means that skill differences matter more in highly productive than in less productive firms. This assumption formalises the idea that a firm with a sophisticated technology, high capital endowment, or a capable management can put employees' skills to more productive uses than a firm lacking such complementary inputs. In short, Assumption 2 requires that the marginal product of 
labour is decreasing (a), that high-ability workers have an absolute advantage in all firms (b), but that high (low) ability workers have a comparative advantage in high (low) productivity firms (c).

Firms cannot observe the true skill level $s$. They do observe, however, the grade $G$ and the social origin $c$ of the student as well as the aggregate extent of grade inflation $\gamma$. To motivate this informational structure, notice that it is fundamentally difficult for an outsider to assess the validity of an individual student's grade, whereas the aggregate grading policy may be known due to reputation effects. Moreover, it seems plausible that a personnel manager can quite easily find out about the social background of a job applicant, say by observing the name, address, manners, clothing, parents' occupation, etc. Based on (1) and (2) one finds the posterior probability $\operatorname{Prob}\{s \mid G(j), c(j) ; \gamma\}$ that worker $j$ is of skill $s=a, b$, conditional on her grade $G(j)$ and class $c(j)$. For the high skill level these probabilities are, for $c=h, \ell$, given by

$$
\begin{aligned}
\operatorname{Prob}\{a \mid A, c ; \gamma\} & =\frac{n_{a c}}{N_{A c}(\gamma)}=\frac{n_{a c}}{n_{a c}+\gamma n_{b c}} \stackrel{\text { def. }}{=} \rho_{c}(\gamma), \\
\operatorname{Prob}\{a \mid B, c ; \gamma\} & =0
\end{aligned}
$$

and for the low skill level they are $\operatorname{Prob}\{b \mid A, c ; \gamma\}=1-\rho_{c}(\gamma)$ and $\operatorname{Prob}\{b \mid B, c ; \gamma\}=$ 1 for $c=h, \ell$. Notice that the grade $B$ fully reveals ability $b$, so that social class does not matter for students with a $B$. Hence, there remain only the three signals $(A, h),(A, \ell), B$ which distinguish workers from the point of view of the firms.

The probabilities in (3) and (4) are used to evaluate the expected output

$$
\varphi(i, j ; \gamma)=\sum_{s=a, b} \operatorname{Prob}\{s \mid G(j), c(j) ; \gamma\} \cdot f_{s}^{\prime}(i)
$$

worker $j$ will produce in firm $i$ if only her signal $(G(j), c(j))$ is known. For a student $j$ with grade $G(j)=A$, from (3), this reduces to

$$
\varphi(i, j ; \gamma)=\rho_{c(j)} f_{a}^{\prime}(i)+\left(1-\rho_{c(j)}\right) f_{b}^{\prime}(i)
$$

A student $j$ with grade $G(j)=B$ is recognised as being of low ability and hence will be attributed the expected output

$$
\varphi(i, j ; \gamma)=f_{b}^{\prime}(i)
$$


Matching. In order to describe the matching between workers and firms, it is convenient to re-arrange the names of workers after grading has occurred so that all workers with signal $(A, h)$ are collected in the interval $J_{A h} \stackrel{\text { def. }}{=}\left[M, M+N_{A h}\right)$, all workers with signal $(A, \ell)$ are located in $J_{A \ell} \stackrel{\text { def. }}{=}\left[M+N_{A h}, M+N_{A}\right)$, and all workers with signal $B$ are placed in the interval $J_{B} \stackrel{\text { def. }}{=}\left[M+N_{A}, M+N\right)$. Writing $\lambda$ for the Lebesgue-measure defined for the Borel-sets contained in $[0, M+N)$, a feasible matching between firms and workers is then defined as follows.

Definition 1 A feasible matching is a Lebesgue-measurable function $\mu:[0, M+$ $N) \rightarrow[0, M+N)$ such that

(a) $\mu(\mu(k))=k \quad$ for all $k \in[0, M+N)$,

(b) $\mu(i) \in[M, M+N) \cup\{i\} \quad$ for all $i \in[0, M)$, $\mu(j) \in[0, M) \cup\{j\} \quad$ for all $j \in[M, M+N)$,

(c) for all Lebesgue-measurable sets $K \subset[0, M+N)$, it holds $\lambda(\mu(K))=\lambda(K)$.

Definition 1 (a) imposes bilateral consistency on the matching function, stating that one's partner's partner is oneself. Part (b) of Definition 1 formalises the two-sidedness of the matching between firms and workers. If a firm $i \in[0, M)$ has a partner, then this must be a worker $j \in[M, M+N)$, and vice versa. If an agent $k$ is unmatched I write $\mu(k)=k$. Finally, Definition 1 (c) says that for any set $K$ of agents, the set of their partners must be of equal measure. This expresses, in the context of an atomless agent space, the idea that each firm offers just one job and each worker works in (at most) one firm. Requirement (c) is thus a market clearing condition stating that the matches formed must be feasible in the aggregate.

Stable assignment. Payoffs $\pi_{i}$ and $\omega_{j}$ of firms and workers are generated from the matching function $\mu$ together with a wage function $w:[0, M) \rightarrow \mathbb{R}_{+}$ describing for each firm $i \in[0, M)$ the wage $w(i)$ it pays. If a firm has a partner, i.e., if $\mu(i) \neq i$ for some $i \in[0, M)$, its payoff is the expected output according to (5) net of the wage paid,

$$
\pi_{i}=\varphi(i, \mu(i) ; \gamma)-w(i)
$$


If a worker has a job, i.e., if $\mu(j) \neq j$ for some $j \in[M, M+N)$, then her payoff is the wage paid by her employer,

$$
\omega_{j}=w(\mu(j)) .
$$

The payoffs of unmatched agents are set to zero, that is for all $i \in[0, M)$ or $j \in[M, M+N)$ with $\mu(i)=i$ or $\mu(j)=j$, one has $\pi_{i}=0$ and $\omega_{j}=0$.

Definition 2 A stable assignment is a feasible matching $\mu$, a wage function $w$ : $[0, M) \rightarrow \mathbb{R}_{+}$and payoffs $\pi_{i}$ for all $i \in[0, M)$ and $\omega_{j}$ for all $j \in[M, M+N)$ generated by $\mu$ and $w$ such that

(a) $\pi_{i} \geq 0$ for all $i \in[0, M)$ and $\omega_{j} \geq 0$ for all $j \in[M, M+N)$

(b) $\pi_{i}+\omega_{j} \geq \varphi(i, j ; \gamma) \quad$ for all $i \in[0, M)$ and $j \in[M, M+N)$.

Part (a) of Definition 2 is an individual rationality constraint stating that no agent does worse in the matching than she would do by staying alone. Definition 2 (b) requires that the sum of the payoffs of any firm and any worker, whether matched together or not, is at least as large as the output this pair could produce together. This condition says that no pair has the potential to improve on their payoffs by matching together. An assignment is thus stable if there is no profitable unilateral or bilateral deviation from the allocation it induces.

In the following section, the set of stable assignments in the labour market is characterised.

\section{The Labour Market}

The first two results show how the information conveyed by grade and social origin determines the matching between workers and firms.

Proposition 1 (Sorting of workers). Consider $\gamma>0$ and let a stable assignment $(\mu, w)$ be given. Then for any two workers $j, j^{\prime}$ who are matched to firms, $\mu(j) \neq j$ and $\mu\left(j^{\prime}\right) \neq j^{\prime}$, and who satisfy (a) $j \in J_{A h}$ and $j^{\prime} \in J_{A \ell} \cup J_{B}$ or (b) $j \in J_{A h} \cup J_{A \ell}$ and $j^{\prime} \in J_{B}$, it holds $\mu(j) \leq \mu\left(j^{\prime}\right)$. 
Proof. See Appendix.

Proposition 1 implies that the three signals $(A, h),(A, \ell)$, and $B$ partition workers in a three-layer hierarchy, with $A$-students from the higher social class forming the top layer, $A$-students from the lower social class forming the middle layer, and $B$-students from both classes forming the bottom layer. Whenever one encounters two employed workers with differing signals, in a stable assignment, the worker from the higher layer necessarily must hold the more productive job.

While this proposition characterises the relative position of individual workers, it does not say anything about how many workers are employed and how many jobs can be filled. These issues are addressed in Proposition 2.

Proposition 2 (Filled jobs and vacancies). Consider $\gamma>0$ and let a stable assignment $(\mu, w)$ be given. Then almost all firms $i<N$ are matched to workers and almost all workers are matched to firms $i<N$, with the more productive firms employing the workers with the better signals, and almost all firms $i \geq N$ are unmatched:

(a) $\lambda\left(\left\{i \in\left[0, N_{A h}\right) \mid \mu(i) \in J_{A h}\right\}\right)=\lambda\left(\left\{j \in J_{A h} \mid \mu(j) \in\left[0, N_{A h}\right)\right\}\right)=N_{A h}$, (b) $\lambda\left(\left\{i \in\left[N_{A h}, N_{A}\right) \mid \mu(i) \in J_{A \ell}\right\}\right)=\lambda\left(\left\{j \in J_{A \ell} \mid \mu(j) \in\left[N_{A h}, N_{A}\right)\right\}\right)=N_{A \ell}$, (c) $\lambda\left(\left\{i \in\left[N_{A}, N\right) \mid \mu(i) \in J_{B}\right\}\right)=\lambda\left(\left\{j \in J_{B} \mid \mu(j) \in\left[N_{A}, N\right)\right\}\right)=N_{B}$, (d) $\lambda(\{i \in[N, M) \mid \mu(i)=i\})=M-N$.

Proof. See Appendix.

Proposition 2 states that in a stable assignment the labour market must be cleared. Since the measure of workers $N$ is less than the measure of firms $M$, market clearing entails that there remains a set of measure $M-N$ of vacant jobs. Moreover, the allocation of workers to firms respects the hierarchy of signals as stated in Proposition 1. Thus, the $N_{A h}$ most productive jobs go to the students with grade $A$ originating from the favoured social class; the next $N_{A \ell}$ somewhat less productive firms employ workers from the middle layer composed of the lower-class $A$-students; in the following $N_{B}$ even less productive firms students with the grade $B$ are active; and finally, the $M-N$ least productive jobs 
Figure 1: Matching in a stable assignment.

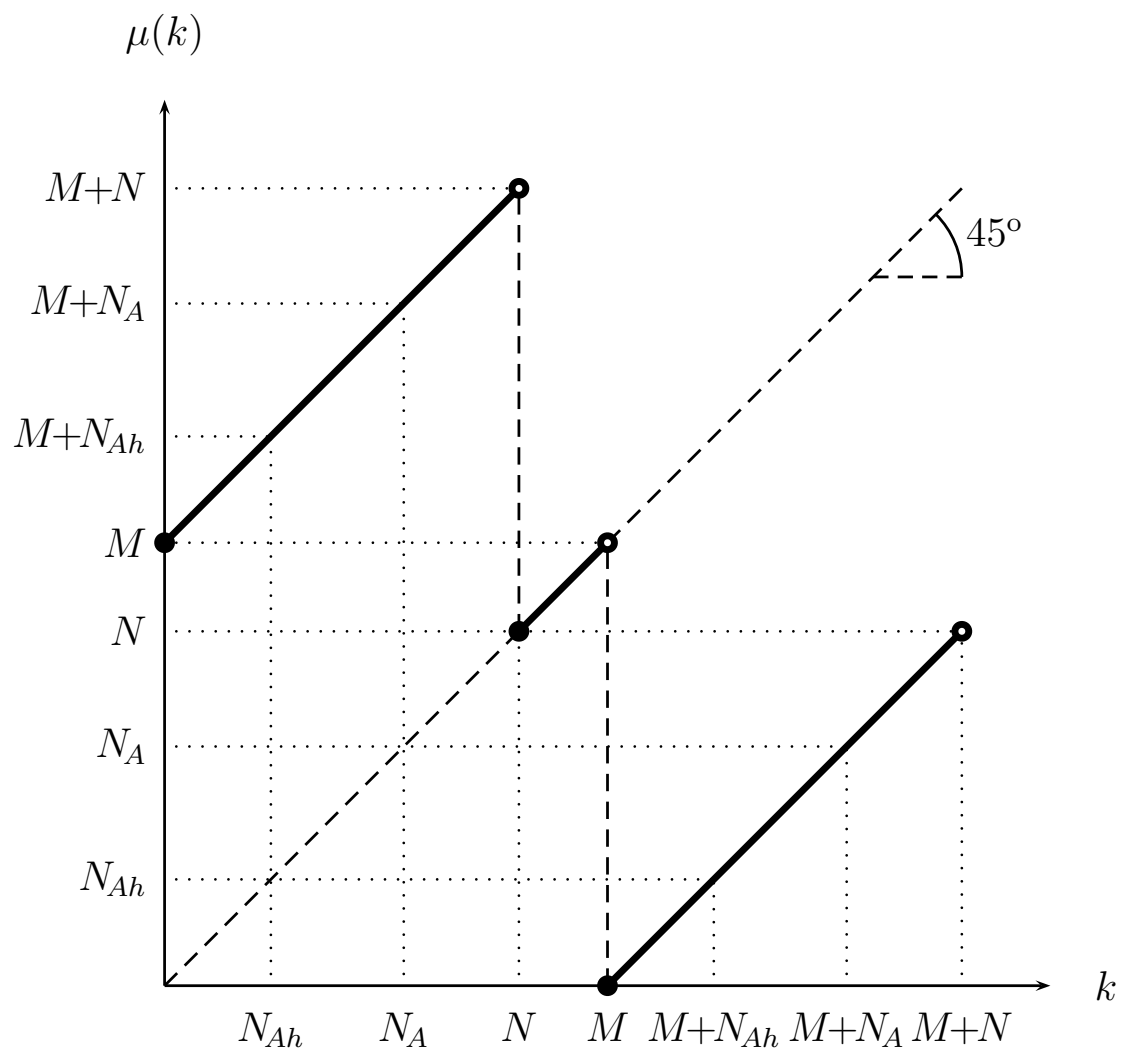

remain unfilled. This matching pattern is induced by the function

$$
\mu(k)=\left\{\begin{array}{cll}
M+k & \text { if } & 0 \leq k<N \\
k & \text { if } \quad N \leq k<M \\
k-M & \text { if } \quad M \leq k<M+N
\end{array}\right.
$$

illustrated in Figure 1, which provides an example for a feasible matching function satisfying Definition 1 and displaying the properties described in Propositions 1 and 2 .

Turning now to the wages, I first compare the wages of two individual employed workers sharing the same signal.

Proposition 3 (Equal pay for equal signal). In a stable assignment with $\gamma>$ 0, two employed workers with the same signal obtain the same wage: If $j, j^{\prime} \in J_{S}$, with $S=A h, A \ell, B$, and $\mu(j) \neq j, \mu\left(j^{\prime}\right) \neq j^{\prime}$, then $w(\mu(j))=w\left(\mu\left(j^{\prime}\right)\right) \stackrel{\text { def. }}{=} w_{S}(\gamma)$. 
Proof. From the definition of payoffs in (8) and (9) and the stability requirement in Definition 2 (b), one has

$$
\pi_{\mu(j)}+\omega_{j^{\prime}}=\varphi(\mu(j), j ; \gamma)-w(\mu(j))+w\left(\mu\left(j^{\prime}\right)\right) \geq \varphi\left(\mu(j), j^{\prime} ; \gamma\right)
$$

Since both workers share the same signal, $j, j^{\prime} \in J_{S}$, expected output would be the same if they worked both in the same firm $\mu(j)$, i.e., $\varphi\left(\mu(j), j^{\prime} ; \gamma\right)=$ $\varphi(\mu(j), j ; \gamma)$. Hence, the inequality in (10) implies $w\left(\mu\left(j^{\prime}\right)\right) \geq w(\mu(j))$. From the stability requirement $\pi_{\mu\left(j^{\prime}\right)}+\omega_{j} \geq \varphi\left(\mu\left(j^{\prime}\right), j ; \gamma\right)$ one derives in the same way that $w(\mu(j)) \geq w\left(\mu\left(j^{\prime}\right)\right)$. Altogether, one must have $w(\mu(j))=w\left(\mu\left(j^{\prime}\right)\right)$.

As Proposition 3 shows, in a stable assignment, the market treats workers fairly in the sense that any two workers which convey the same signal about their productivity earn the same wage. In a context of incomplete information created by grade inflation, however, identical signals need not mean identical productivity, and differing signals need not mean different productivities. Thus, a low skilled student who was lucky to obtain an $A$ will be treated like a high skilled student from the same social origin. Similarly, an able student from the lower social class will not receive the same wage as an able student from the higher class, although they both have exactly the same skills.

The following proposition quantifies the signal-specific wages obtained in a stable assignment.

Proposition 4 (Wages). In a stable assignment with $\gamma>0$, wages are

$$
\begin{aligned}
& \text { (a) } w_{B}(\gamma)=f_{b}^{\prime}(N) \stackrel{\text { def. }}{=} w_{B} \\
& \text { (b) } w_{A \ell}(\gamma)=w_{B}+\rho_{\ell}(\gamma)\left[f_{a}^{\prime}\left(N_{A}\right)-f_{b}^{\prime}\left(N_{A}\right)\right] \\
& \text { (c) } w_{A h}(\gamma)=w_{A \ell}(\gamma)+\left[\rho_{h}(\gamma)-\rho_{\ell}(\gamma)\right]\left[f_{a}^{\prime}\left(N_{A h}\right)-f_{b}^{\prime}\left(N_{A h}\right)\right]
\end{aligned}
$$

Proof. See Appendix.

According to Proposition 4 (a) and (b), the students with signal $(A, \ell)$ obtain a wage premium compared to the students with the bad grade $B$. This premium expresses the market valuation of the better grade and is therefore called the

$$
\text { grade premium: } \operatorname{GRA}(\gamma) \stackrel{\text { def. }}{=} \rho_{\ell}(\gamma)\left[f_{a}^{\prime}\left(N_{A}(\gamma)\right)-f_{b}^{\prime}\left(N_{A}(\gamma)\right)\right] \text {. }
$$


Its value is determined by the productivity differential of the last $A$-student times the probability that this student is in fact of high ability. Since high ability students are more productive than low ability students (Assumption $2 \mathrm{~b}$ ), the grade premium is positive for all $0<\gamma \leq 1$.

Similarly, from Proposition 4 (b) and (c), the $A$-students originating from the higher social class obtain a wage premium relative to the lower class $A$-students, called the

social premium: $\operatorname{SOC}(\gamma) \stackrel{\text { def. }}{=}\left[\rho_{h}(\gamma)-\rho_{\ell}(\gamma)\right]\left[f_{a}^{\prime}\left(N_{A h}(\gamma)\right)-f_{b}^{\prime}\left(N_{A h}(\gamma)\right)\right\}(12)$ Assumption 1 implies that $\rho_{h}(\gamma)>\rho_{\ell}(\gamma)$ if $\gamma>0$. With Assumption 2 (b) it then follows that the social premium is strictly positive if $\gamma>0$. This shows that, in a situation where grades are inflated, employers interpret a favourable social origin as an additional signal for high ability. In the market, this valuation by firms is cashed in by the higher class $A$-students in the form of a wage differential relative to their lower class counterparts. Its value is the product of the productivity differential between both skill levels, evaluated at the last $(A, h)$-student, times the difference in posteriors attached to $A$-students of both classes. It so expresses by how much the expected productivity of a higher-class $A$-student exceeds the one of a lower-class $A$-student.

The premia are illustrated in Figure 2. There, the upper (lower) bold line gives the expected output of a higher (lower) class worker with grade $A$. The grade premium is such that the last firm able to hire an $A$-student, i.e., firm $i=N_{A}$, is indifferent between hiring this student and a student of low ability. Geometrically, the grade premium is then the difference between the lower bold curve and the marginal product $f_{b}^{\prime}$, both evaluated at $N_{A}$. Similarly, the social premium is determined by the choice of the last firm able to find an upper class student with an $A$, i.e., firm $i=N_{A h}$. This firm must be indifferent between hiring such a student and an $A$-student from the disfavoured origin. The difference between the expected productivities of these two students, geometrically expressed by the vertical jump between both bold curves occurring at $N_{A h}$, is the social premium.

To conclude this section, a remark is in order concerning the behaviour of the model when $\gamma=0$. With honest grading, the three signals collapse to two which are exclusively defined by the grades $A$ and $B$. This occurs because in this case, 
Figure 2: Wages in a stable assignment.

marginal

product

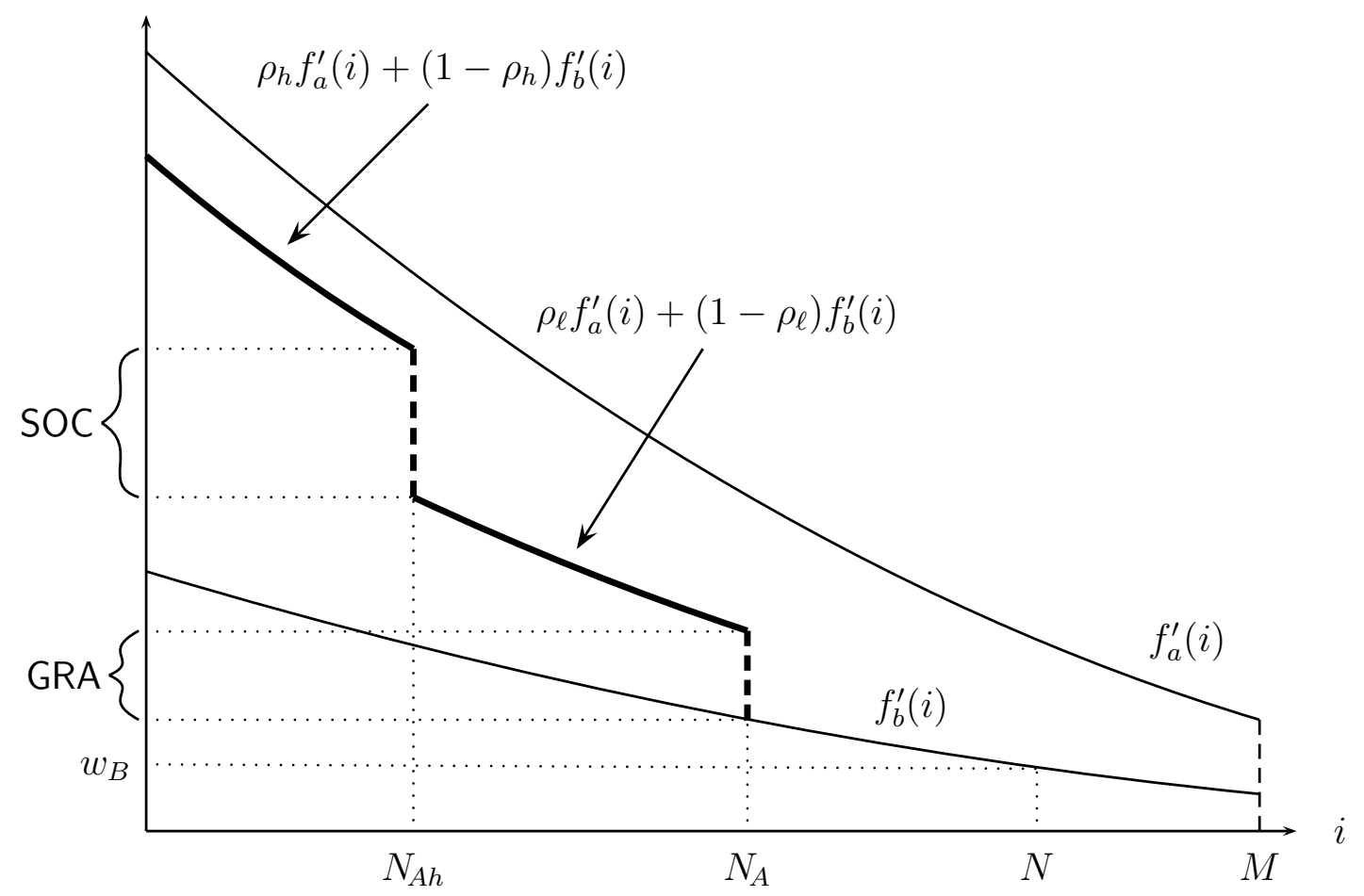

the grade $A$ fully reveals high ability so that there is no reason to differentiate workers with this grade according to social origin. Because of this discontinuity, Propositions 1 to 4 cannot literally be extended to $\gamma=0$. However, one can easily state modified versions of these propositions for this case, with the wage for the high grade being $w_{A}=w_{B}+f_{a}^{\prime}\left(n_{a}\right)-f_{b}^{\prime}\left(n_{a}\right)$. Now the grade premium converges to $f_{a}^{\prime}\left(n_{a}\right)-f_{b}^{\prime}\left(n_{a}\right)$ and the social premium converges to zero if $\gamma \rightarrow 0$. Hence, the wages are continuous at $\gamma=0$, even though the underlying matching need not be.

In the following section, it is analysed how the wages are affected by changes in the grade inflation parameter, and which students benefit from such changes. 


\section{Winners and Losers From Grade Inflation}

Using Proposition 4, one can derive the expected wages $w_{s c}, s=a, b$ and $c=\ell, h$, obtained by the four different types of workers in the economy. Since students with a high ability certainly obtain grade $A$, the wage of high ability students originating from social class $c=h, \ell$ is the wage paid to $A$-students from this class, $w_{a c}(\gamma)=w_{A c}(\gamma)$. For low ability students the expected wage is a weighted average of the wage obtained by $B$ - and by $A$-students of the corresponding origin, $w_{b c}(\gamma)=(1-\gamma) w_{B}+\gamma w_{A c}(\gamma)$ for $c=\ell, h$.

In order to analyse which group, if any, benefits from a deviation from honest grading, I consider for each type $(s, c)$, for $s=a, b$ and $c=h, \ell$, the grade inflation parameter $\gamma_{s c} \stackrel{\text { def. }}{=} \operatorname{argmax}_{\gamma}\left\{w_{s c}(\gamma) \mid 0 \leq \gamma \leq 1\right\}$ which is most preferred by this type. In order to characterise the preferred grading policies, the following derivatives (13) to (16) which can straightforwardly be calculated from Proposition 4 are useful.

$$
\begin{aligned}
w_{a \ell}^{\prime}(\gamma) & =\operatorname{GRA}^{\prime}(\gamma) \\
w_{b \ell}^{\prime}(\gamma) & =\gamma \operatorname{GRA}^{\prime}(\gamma)+\operatorname{GRA}(\gamma) \\
w_{a h}^{\prime}(\gamma) & =\operatorname{GRA}^{\prime}(\gamma)+\operatorname{SOC}^{\prime}(\gamma) \\
w_{b h}^{\prime}(\gamma) & =\gamma\left[\operatorname{GRA}^{\prime}(\gamma)+\operatorname{SOC}^{\prime}(\gamma)\right]+[\operatorname{GRA}(\gamma)+\operatorname{SOC}(\gamma)]
\end{aligned}
$$

Consider first the low-ability students of both social origins. When determining her preferred grading policy, such a student faces a trade-off between two effects of an increase in grade inflation expressed by the two terms on the right-hand-sides of (14) and (16). On the one hand, with increased grade inflation, it becomes more likely that this student obtains an undeserved $A$, and so it becomes more likely that she receives the grade premium and, if she is of the higher class, the social premium (the second terms in (14) and (16)). Since the premia are positive, from this effect low ability students would like to see more grade inflation. On the other hand, the premia themselves are affected if more workers with grade $A$ enter the labour market (the first terms in (14) and (16)). Low ability students care about this effect since, in a situation with grade inflation, they sometimes also obtain an $A$. Therefore, also low ability students do not necessarily want to push grade inflation ever further. If in the initial situation grading is honest, however, the 
second effect is not relevant since a low ability student does not get any premium in the first place. By consequence, at $\gamma=0$ the positive effect dominates so that a little grade inflation is always beneficial for low skilled students.

Turning now to the high ability students from the lower social class, one sees from (13) that their preference is determined by the change in the grade premium $\operatorname{GRA}^{\prime}(\gamma)$ induced by stronger grade inflation. This change occurs through two channels. Firstly, when employers assess an $A$-student, they attach a lower posterior to her being of truly high skill, $\rho_{\ell}^{\prime}(\gamma)<0$, since there are more low ability students in the pool of those who are awarded an $A$. Secondly, from Assumption 2 (c), also the productivity differential $f_{a}^{\prime}\left(N_{A}\right)-f_{b}^{\prime}\left(N_{A}\right)$ decreases since the total number $N_{A}$ of $A$-students increases. Thus, through both channels, the grade premium is eroded if grades are inflated, $\operatorname{GRA}^{\prime}(\gamma)<0$ for all $0 \leq \gamma \leq 1$. This implies that any increase in grade inflation makes the able, lower class students definitely worse off.

In order to assess, finally, the preferences of the high skilled students from favourable backgrounds, consider an example where $n_{a h}=n_{a \ell}=1 / 4, n_{b h}=$ $0, n_{b \ell}=1 / 2$, and $f_{a}(i)-f_{b}(i)=\ln (i+1)$. In this example, one finds $w_{a h}(0)=$ $w_{B}+2 / 3$ whereas $w_{a h}(1)=w_{B}+7 / 10$. Thus, full grade inflation is preferred by these agents to honest grading; indeed, by some (tedious) computing, one finds for this example $w_{a h}^{\prime}(\gamma)>0$ for all $0 \leq \gamma \leq 1$ so that $\gamma_{a h}=1$ is in fact the optimum. By continuity, this corner solution remains valid even after small perturbations of the parameters, notably so that $n_{b h}>0$.

The following proposition summarises these results.

\section{Proposition 5 (Preferences for grade inflation).}

(a) Low ability students always prefer some grade inflation, $\gamma_{b c}>0$ for both $c=h, \ell$.

(b) High-ability students from a disfavoured background prefer honest grading, $\gamma_{a \ell}=0$.

(c) There are production functions $f_{s}, s=a, b$, and population shares $n_{s c}$, for $s=a, b$ and $c=h, \ell$, satisfying Assumptions 1 and 2 , such that $\gamma_{a h}=1$. 
While the first two results in Proposition 5 correspond to intuition and probably to the experience of most teachers, part (c) is rather surprising. It states that high ability students of favourable origin, which one may call the "elite", may opt for full grade inflation. Just like the able students from the lower class, these students suffer from an erosion of the grade premium, and would, from this effect alone, oppose grade inflation. However, grade inflation allows the high class students to obtain the social premium which is absent with honest grading. The example presented above shows that this second effect can over-compensate the erosion of the grade premium so that grade inflation is beneficial for the "elite".

To understand the economic forces driving this result, notice that the high-class, high-ability ah-students face two kinds of competition on the labour market, from the low ability, high-class bh-students and from the high-ability, low-class $a \ell$-students. Grade inflation induces employers to confound the $a h$-students with the $b h$-students, so that for the $a h$-students, competition by $b h$-students is exacerbated by grade inflation. With honest grading, on the other hand, employers recognise that the $a \ell$-students are just as productive as the $a h$-students. Honest grading therefore raises the number of students who display the best signal available in the market and thereby depresses the wage obtainable by the $a h$ students who hold this signal. Put differently, grade inflation shields the highly skilled students with upper class backgrounds from competition by the equally able students originating from disadvantaged social classes. Consequently, from this effect alone, the $a h$-students would prefer grade inflation. When $a h$-students choose their most preferred grading policy, they have to figure out whose competition is more harmful for them. As the example shows, this may be the a $\ell$-group, in particular when the number of these students is very large relative to the number of $b h$-students.

In addition to type-specific preferences for grade inflation as analysed in Proposition 5, one might as well be interested in the overall impact of grade inflation on a social class. Specifically, one might wonder whether lenient grading helps or hurts the students from disfavoured backgrounds. To address this question, define

$$
W_{c}(\gamma) \stackrel{\text { def. }}{=} n_{a c} w_{a c}(\gamma)+n_{b c} w_{b c}(\gamma)
$$

as the aggregate wage income received by workers from social origin $c=h, \ell$. 


\section{Proposition 6 (Grade inflation and social origin).}

The aggregate wage of lower class workers strictly decreases if grades are inflated more strongly:

$$
W_{\ell}^{\prime}(\gamma)<0 \quad \text { for all } 0 \leq \gamma \leq 1 .
$$

Proof. Replacing $w_{a \ell}(\gamma)=w_{A \ell}(\gamma)$ and $w_{b \ell}(\gamma)=\gamma w_{A \ell}+(1-\gamma) w_{B}$ with the help of Proposition 4 and using (3), equation (17) becomes $W_{\ell}(\gamma)=n_{a \ell}\left[f_{a}^{\prime}\left(N_{A}\right)-\right.$ $\left.f_{b}^{\prime}\left(N_{A}\right)\right]+n_{\ell} w_{B}$. Noting $\partial N_{A} / \partial \gamma=n_{b}$, differentiating yields

$$
\frac{\partial W_{\ell}(\gamma)}{\partial \gamma}=n_{a \ell} n_{b}\left[f_{a}^{\prime \prime}\left(N_{A}\right)-f_{b}^{\prime \prime}\left(N_{A}\right)\right]<0,
$$

with the sign following on Assumption 2 (c).

Proposition 6 says that grade inflation unambiguously hurts the lower classes, and that, consequently, honest grading is optimal if one wants to promote the welfare of socially disadvantaged students. At the heart of this result is the informational structure of the present model. Lower class students are less able on average, so that one might think that camouflaging academic performance by inflated grades allows these students to grasp some jobs which otherwise would be reserved to students with proven skills. This argument, however, misses the fact that social origin is observable irrespective of the grading scheme. Thus, employers cannot be fooled into disregarding the lower average ability of disadvantaged students. The only result achieved by grade inflation is that the assessment of abilities is distributed differently among the lower class students. The low-ability students from this class gain by grade inflation, but this gain comes exclusively at the expense of the high ability students of the same background. In addition, grade inflation reduces the wage for students with good grades, so that wage income is not only redistributed among the lower class agents but decreases overall.

So far, the analysis was restricted to highlighting the preferences of the individual subgroups of the student population. In the following, I give some hints as to what grading policy might actually be chosen. Clearly, the answer to this question strongly depends on the political institution governing the choice of grading policies. In this respect, in the present paper only a first step is attempted, by restricting attention to median voter results. That is, the students, or, more realistically, the parents who care for their offspring vote on alternative grading 
schemes $\gamma$. The decision is given by a Condorcet winner, i.e., a grading scheme $\gamma$ such that no other grading scheme $\gamma^{\prime}$ gains a majority in a pairwise vote between $\gamma$ and $\gamma^{\prime}$.

For this part of the analysis, it is convenient to define the elasticities of the grade premium and the social premium by $\alpha(\gamma) \stackrel{\text { def. }}{=} \gamma \operatorname{GRA}^{\prime}(\gamma) / \operatorname{GRA}(\gamma)$ and $\sigma(\gamma) \stackrel{\text { def. }}{=}$ $\gamma \operatorname{SOC}^{\prime}(\gamma) / \operatorname{SOC}(\gamma)$. These elasticities measure how strongly both premia react to an increase in grade inflation. Since the grade premium necessarily decreases with grade inflation, $\alpha(\gamma)<0$. The elasticity of the social premium, however, may have both signs, depending on the initial value of $\gamma$ and the curvature of the production functions.

\section{Proposition 7 (Voting).}

(a) The grading scheme $\gamma_{b \ell}$ preferred by the low-ability, low-class students is the Condorcet winner in a vote among students if $n_{b}>N / 2, n_{\ell}>N / 2$, and $\sigma(\gamma)>-1$ for all $\gamma \leq \gamma_{b \ell}$.

(b) The grading scheme $\gamma_{a h}$ preferred by the high-ability, high-class students is the Condorcet winner in a vote among students if $n_{a}>N / 2, n_{h}>N / 2$, and for all $\gamma \leq \gamma_{a h}$,

$$
\frac{\operatorname{GRA}(\gamma)}{\operatorname{SOC}(\gamma)}>-\frac{1-\frac{1-\gamma}{\gamma} \sigma(\gamma)}{1-\frac{1-\gamma}{\gamma} \alpha(\gamma)}
$$

Proof of Proposition 7. See Appendix.

In case (a) of Proposition 7 the low ability, low class students of type $(b, \ell)$ decide on the extent of grade inflation. Depending on the alternative, they achieve this by the support of either the $(a, \ell)$ - or the $(b, h)$-students, provided that each of these groups forms a majority together with the $(b, \ell)$-students. To see why, remember that the $(a, \ell)$-students are strictly worse off by any increase in grade inflation and so always vote for the lower grade inflation parameter on offer. Thus, they will vote for $\gamma_{b \ell}$ if the alternative $\gamma^{\prime}$ is larger. When the alternative $\gamma^{\prime}$ is smaller than $\gamma_{b \ell}$, the $(b, \ell)$-students will be supported by the $(b, h)$-students provided that these prefer at least as much grade inflation as the $(b, \ell)$-students. 
Now the wages of these two groups differ in that the $(b, h)$-students obtain the social premium with probability $\gamma$. A marginal increase in $\gamma$ is therefore valued higher by the $(b, h)$-students than by the $(b, \ell)$-students if the expected social premium $\gamma \mathrm{SOC}(\gamma)$ increases in $\gamma$. This is the case if the social premium decreases less than proportionally in $\gamma$, or equivalently, if the elasticity of the social premium $\sigma(\gamma)$ is larger than -1 . Then, the $(b, h)$-students are even more enthusiastic about inflating grades than the $(b, \ell)$-students.

Case (b) of Proposition 7 shows that in some circumstances also the "elite" $(a, h)$-students can impose their preferred grade inflation democratically. Like the $(b, \ell)$-students in case $(a)$, they build on the support by the $(a, \ell)$-students whenever some $\gamma^{\prime}$ is proposed which exceeds their most preferred grade inflation $\gamma_{a h}$. If a smaller alternative $\gamma^{\prime}$ is on the ballot then the $(b, h)$-students vote for $\gamma_{a h}$ provided that these students like grade inflation at least as much as the $(a, h)$ students. Condition (18) ensures that this is the case. Although this condition looks rather involved, it is actually not very strong. The interesting case here is the situation where the social premium increases with increasing grade inflation, so that $\sigma(\gamma)>0$. In this case the right-hand-side of (18) may turn positive and so the condition (18) might fail. To avoid this, in essence, the elasticity of the social premium $\sigma(\gamma)$ must not be too large. That means that the social premium does not increase too fast with increasing grade inflation. Otherwise, with a fast increasing social premium, the $(a, h)$-students who obtain the social premium with certainty might benefit even more by increasing grade inflation than the $(b, h)$-students who obtain the premium only with probability $\gamma$.

The assumptions used to show Proposition 7 are quite special - an observation which is not uncommon for median voter results. Thus, this proposition does not attempt to fully characterise the outcome of a democratic choice of grading policies. Rather it serves to highlight which groups of students may form potential political coalitions. In both cases, preferences for grading policies do not only follow the obvious split according to ability, but can as well be aligned according to social origin. Specifically, as case (b) shows, the high-ability high-class students may join forces with their low ability counterparts of the same social origin so as to impose some grade inflation which hurts the high ability, low class students. 


\section{Conclusion}

In this paper, it was analysed how a grading policy which awards good grades to mediocre students affects the labour market. It was shown that such grade inflation benefits students of low ability, but that it hurts students from disadvantaged social backgrounds. Moreover, grade inflation may benefit students from favoured social origins because it devalues the good grades earned by aspiring lower class students, thereby reducing competition for attractive jobs. For education policy, these results suggest that lenient grading is not a suitable means for promoting equality of opportunities. Quite the contrary, a strictly meritocratic system where performance is measured and documented objectively is the best way to induce social mobility.

These results were derived in a model of two-sided matching between firms and workers. This approach, which provides a microeconomic foundation for the allocative role of grades, lends itself to a number of extensions, two of which I briefly discuss. Firstly, it seems natural to extend the model of a centralised grading authority presented in the present paper to a model where several schools, or school districts, set their own grading policies. In such a model one could answer questions such as whether decentralised grades are necessarily, as is often claimed, less stringent than centrally chosen grades, or whether decentralisation hurts low ability and/or lower class students. As a second extension, one might consider to integrate the matching model with a signalling approach where the grading policy of the schooling system is not observable. It would be an interesting, though challenging, task to find out whether honest grading can survive in an equilibrium in such a model.

\section{Appendix}

Proof of Proposition 1. Write $i=\mu(j)$ and $i^{\prime}=\mu\left(j^{\prime}\right)$. From Definition 2 (b), stability requires $\pi_{i}+\omega_{j^{\prime}} \geq \varphi\left(i, j^{\prime} ; \gamma\right)$ and $\pi_{i^{\prime}}+\omega_{j} \geq \varphi\left(i^{\prime}, j ; \gamma\right)$. Replacing the payoffs by (8) and (9) and using the bilateral consistency requirements $\mu(i)=j$ and $\mu\left(i^{\prime}\right)=j^{\prime}$ according to Definition 1 (a) shows that these two inequalities are 
equivalent to $\varphi(i, j ; \gamma)-w(i)+w\left(i^{\prime}\right) \geq \varphi\left(i, j^{\prime} ; \gamma\right)$ and $\varphi\left(i^{\prime}, j^{\prime} ; \gamma\right)-w\left(i^{\prime}\right)+w(i) \geq$ $\varphi\left(i^{\prime}, j ; \gamma\right)$. Adding these inequalities, one arrives at

$$
\varphi(i, j ; \gamma)+\varphi\left(i^{\prime}, j^{\prime} ; \gamma\right) \geq \varphi\left(i, j^{\prime} ; \gamma\right)+\varphi\left(i^{\prime}, j ; \gamma\right)
$$

One has either $G(j)=A$ and $G\left(j^{\prime}\right)=B$ or $G(j)=G\left(j^{\prime}\right)=A$ and $c(j)=h$, $c\left(j^{\prime}\right)=\ell$. Starting with the first possibility and using (6) and (7), one finds

$$
\begin{aligned}
\varphi(i, j ; \gamma) & =\rho_{c(j)} f_{a}^{\prime}(i)+\left(1-\rho_{c(j)}\right) f_{b}^{\prime}(i) \\
\varphi\left(i^{\prime}, j^{\prime} ; \gamma\right) & =f_{b}^{\prime}\left(i^{\prime}\right) \\
\varphi\left(i, j^{\prime} ; \gamma\right) & =f_{b}^{\prime}(i) \\
\varphi\left(i^{\prime}, j ; \gamma\right) & =\rho_{c(j)} f_{a}^{\prime}\left(i^{\prime}\right)+\left(1-\rho_{c(j)}\right) f_{b}^{\prime}\left(i^{\prime}\right) .
\end{aligned}
$$

Inserting these in (A.1) yields $\rho_{c(j)}\left[f_{a}^{\prime}(i)-f_{b}^{\prime}(i)\right] \geq \rho_{c(j)}\left[f_{a}^{\prime}\left(i^{\prime}\right)-f_{b}^{\prime}\left(i^{\prime}\right)\right]$. From $\rho_{c(j)}>0$ and Assumption 2 (c), this implies $i \leq i^{\prime}$.

Turning now to the second possibility and using $G(j)=G\left(j^{\prime}\right)=A$ and $c(j)=h$, $c\left(j^{\prime}\right)=\ell$ in $(6)$, one obtains

$$
\begin{aligned}
\varphi(i, j ; \gamma) & =\rho_{h} f_{a}^{\prime}(i)+\left(1-\rho_{h}\right) f_{b}^{\prime}(i), \\
\varphi\left(i^{\prime}, j^{\prime} ; \gamma\right) & =\rho_{\ell} f_{a}^{\prime}\left(i^{\prime}\right)+\left(1-\rho_{\ell}\right) f_{b}^{\prime}\left(i^{\prime}\right), \\
\varphi\left(i, j^{\prime} ; \gamma\right) & =\rho_{\ell} f_{a}^{\prime}(i)+\left(1-\rho_{\ell}\right) f_{b}^{\prime}(i), \\
\varphi\left(i^{\prime}, j ; \gamma\right) & =\rho_{h} f_{a}^{\prime}\left(i^{\prime}\right)+\left(1-\rho_{h}\right) f_{b}^{\prime}\left(i^{\prime}\right) .
\end{aligned}
$$

Inserting these expressions, one derives that (A.1) is equivalent to

$$
\begin{aligned}
& \rho_{h} f_{a}^{\prime}(i)+\left(1-\rho_{h}\right) f_{b}^{\prime}(i)+\rho_{\ell} f_{a}^{\prime}\left(i^{\prime}\right)+\left(1-\rho_{\ell}\right) f_{b}^{\prime}\left(i^{\prime}\right) \\
& \quad \geq \rho_{\ell} f_{a}^{\prime}(i)+\left(1-\rho_{\ell}\right) f_{b}^{\prime}(i)+\rho_{h} f_{a}^{\prime}\left(i^{\prime}\right)+\left(1-\rho_{h}\right) f_{b}^{\prime}\left(i^{\prime}\right) .
\end{aligned}
$$

After replacing $\rho_{h}$ and $\rho_{\ell}$ with the help of (3), this inequality is equivalent to

$$
\begin{aligned}
& \frac{n_{a h} f_{a}^{\prime}(i)+\gamma n_{b h} f_{b}^{\prime}(i)}{n_{a h}+\gamma n_{b h}}+\frac{n_{a \ell} f_{a}^{\prime}\left(i^{\prime}\right)+\gamma n_{b \ell} f_{b}^{\prime}\left(i^{\prime}\right)}{n_{a \ell}+\gamma n_{b \ell}} \\
& \geq \frac{n_{a \ell} f_{a}^{\prime}(i)+\gamma n_{b \ell} f_{b}^{\prime}(i)}{n_{a \ell}+\gamma n_{b \ell}}+\frac{n_{a h} f_{a}^{\prime}\left(i^{\prime}\right)+\gamma n_{b h} f_{b}^{\prime}\left(i^{\prime}\right)}{n_{a h}+\gamma n_{b h}} .
\end{aligned}
$$

Cross-multiplying the denominators, one finds that this is further equivalent to

$$
\left[n_{a h} f_{a}^{\prime}(i)+\gamma n_{b h} f_{b}^{\prime}(i)\right]\left(n_{a \ell}+\gamma n_{b \ell}\right)+\left[n_{a \ell} f_{a}^{\prime}\left(i^{\prime}\right)+\gamma n_{b \ell} f_{b}^{\prime}\left(i^{\prime}\right)\right]\left(n_{a h}+\gamma n_{b h}\right)
$$




$$
\begin{aligned}
& \quad \geq\left[n_{a \ell} f_{a}^{\prime}(i)+\gamma n_{b \ell} f_{b}^{\prime}(i)\right]\left(n_{a h}+\gamma n_{b h}\right)+\left[n_{a h} f_{a}^{\prime}\left(i^{\prime}\right)+\gamma n_{b h} f_{b}^{\prime}\left(i^{\prime}\right)\right]\left(n_{a \ell}+\gamma n_{b \ell}\right) \\
& \Longleftrightarrow \quad \gamma n_{a h} n_{b \ell} f_{a}^{\prime}(i)+\gamma n_{b h} n_{a \ell} f_{b}^{\prime}(i)+\gamma n_{b h} n_{a \ell} f_{a}^{\prime}\left(i^{\prime}\right)+\gamma n_{a h} n_{b \ell} f_{b}^{\prime}\left(i^{\prime}\right) \\
& \geq \gamma n_{b h} n_{a \ell} f_{a}^{\prime}(i)+\gamma n_{a h} n_{b \ell} f_{b}^{\prime}(i)+\gamma n_{a h} n_{b \ell} f_{a}^{\prime}\left(i^{\prime}\right)+\gamma n_{b h} n_{a \ell} f_{b}^{\prime}\left(i^{\prime}\right) .
\end{aligned}
$$

Collecting terms, one arrives at

$$
\gamma\left(n_{a h} n_{b \ell}-n_{b h} n_{a \ell}\right)\left[f_{a}^{\prime}(i)-f_{b}^{\prime}(i)\right] \geq \gamma\left(n_{a h} n_{b \ell}-n_{b h} n_{a \ell}\right)\left[f_{a}^{\prime}\left(i^{\prime}\right)-f_{b}^{\prime}\left(i^{\prime}\right)\right] .
$$

From Assumption 1, one has $n_{a h} n_{b \ell}>n_{b h} n_{a \ell}$. With $\gamma>0$ it follows that (A.2) is equivalent to $f_{a}^{\prime}(i)-f_{b}^{\prime}(i) \geq f_{a}^{\prime}\left(i^{\prime}\right)-f_{b}^{\prime}\left(i^{\prime}\right)$. From Assumption $2(\mathrm{c})$, this again implies $i \leq i^{\prime}$.

Proof of Proposition 2. I first prove that almost all firms $i<N$ are matched to workers,

$$
\lambda(\{i \in[0, N) \mid \mu(i) \in[M, M+N)\})=N .
$$

Assume that (A.3) false. Then there is a set of firms $I \subset[0, N)$ with positive measure $\lambda(I)>0$ such that $\mu(I) \cap[M, M+N)=\emptyset$. Notice that this implies $\mu(i)=i$ and hence $\pi_{i}=0$ for all $i \in I$. From the feasibility requirement in Definition 1 (c), there must be a set of workers $J \subset[M, M+N)$ of equal measure $\lambda(J)=\lambda(I)$ who are not matched to firms in $[0, N)$, i.e., $\mu(J) \cap[0, N)=\emptyset$, and hence $\mu(J) \subset J \cup[N, M)$. Thus, there must be a worker $j \in J$ who has no job, $\mu(j)=j$, or who is matched to a firm $\mu(j) \in[N, M)$.

Consider first the possibility $\mu(j)=j$. This implies $\omega_{j}=0$. Since for any $i \in I$, one has $\pi_{i}=0$, the stability requirement in Definition 2 (b) implies $0=\pi_{i}+\omega_{j} \geq \varphi(i, j ; \gamma)$. Since expected output must be strictly positive from Assumption 2 (b), one arrives at a contradiction.

Consider now the possibility $\mu(j) \in[N, M)$. Individual rationality in Definition 2 (a) implies $\pi_{\mu(j)}=\varphi(\mu(j), j ; \gamma)-w(\mu(j)) \geq 0$. For any $i \in I$, one must then have $\pi_{i}+\omega_{j}=0+w(\mu(j)) \leq \varphi(\mu(j), j ; \gamma)$. Moreover, since $i<N \leq \mu(j)$, it follows from Assumption 2 (a) that $\varphi(\mu(j), j ; \gamma)<\varphi(i, j ; \gamma)$. Hence, one arrives at $\pi_{i}+\omega_{j}<\varphi(i, j ; \gamma)$, contradicting the stability requirement in Definition 2 (b). This establishes (A.3).

(a) The first equality follows from noting that by bilateral consistency in Definition 1 (a), $\left\{j \in J_{A h} \mid \mu(j) \in\left[0, N_{A h}\right)\right\}=\mu\left(\left\{i \in\left[0, N_{A h}\right) \mid \mu(i) \in J_{A h}\right\}\right)$ and 
hence, from feasibility in Definition 1 (c), both sets must have equal measure. Assume that this measure is strictly less than $N_{A h}$. Then from (A.3), there is a set $I \subset\left[0, N_{A h}\right)$ with positive measure $\lambda(I)>0$ such that $\mu(I) \subset J_{A \ell} \cup J_{B}$. Thus, there must be a set $J \subset J_{A h}$ of workers with the same measure $\lambda(J)=\lambda(I)$ who cannot find a partner among the firms $i \in\left[0, N_{A h}\right)$. From (A.3), almost all of these workers are matched to some firms, and hence one can choose $j \in J$ such that $\mu(j) \in\left[N_{A h}, N\right)$. Choose in addition $i \in I$ with the partner $\mu(i)$. Both workers $\mu(i)$ and $j$ are matched to firms. Moreover, it holds $j \in J_{A h}$ and $\mu(i) \in J_{A \ell} \cup J_{B}$. From Proposition 1 (a), this implies $\mu(j) \leq \mu(\mu(i))=i$. However, since $i \in I \subset\left[0, N_{A h}\right)$ and $\mu(j) \in\left[N_{A h}, N\right)$, one also has $i<N_{A h} \leq \mu(j)$, a contradiction.

(b) and (c) The proofs of claims (b) and (c) parallel the one of claim (a) and so are omitted for brevity.

(d) From (A.3) and market clearing in Definition 1 (c), there is at most a zero measure set of workers left for the firms $i \in[N, M), \lambda(\{i \in[N, M) \mid \mu(i) \in$ $[M, M+N)\})=0$. The complement set of unmatched firms must therefore have full measure, $\lambda(\{i \in[N, M) \mid \mu(i)=i\})=M-N$.

Proof of Proposition 4. (a) From Proposition 2 (c), there exists a sequence of firms $i \in\left[N_{A}, N\right)$ such that all $i$ in the sequence are matched to workers $\mu(i) \in J_{B}$ and such that the sequence converges to $N$. From Proposition 3, for all those $i$, one has $w(i)=w_{B}(\gamma)$. Individual rationality in Definition 2 (a) requires for all those $i$ that $\pi_{i}=\varphi(i, \mu(i) ; \gamma)-w(i)=f_{b}^{\prime}(i)-w_{B}(\gamma) \geq 0$, where the second equality follows from (7). Taking the limit as $i \rightarrow N$ yields $w_{B}(\gamma) \leq f_{b}^{\prime}(N)$

From Proposition $2(\mathrm{~d})$, one can find a sequence of unmatched firms $i \in[N, M)$ converging to $N$. Note that for all $i$ in this sequence, one has $\pi_{i}=0$, and take some $j \in J_{B}$ who is matched to a firm so that $w(\mu(j))=w_{B}(\gamma)$. Then, stability in Definition 2 (b) implies together with $(7): \pi_{i}+\omega_{j}=0+w_{B}(\gamma) \geq \varphi(i, j ; \gamma)=f_{b}^{\prime}(i)$. Taking the limit as $i \rightarrow N$, one finds $w_{B}(\gamma) \geq f_{b}^{\prime}(N)$. Thus, $w_{B}(\gamma)=f_{b}^{\prime}(N)$.

(b) From Proposition 2 (b), there exists a sequence of firms $i \in\left[N_{A h}, N_{A}\right)$ such that all $i$ in the sequence are matched to workers $\mu(i) \in J_{A \ell}$ and such that the 
sequence converges to $N_{A}$. From Proposition 3, all those firms pay the same wage $w_{A \ell}(\gamma)$ and so obtain payoff $\pi_{i}=\varphi(i, \mu(i) ; \gamma)-w_{A \ell}(\gamma)$. Consider a worker $j \in J_{B}$ who is matched to some firm and obtains payoff $\omega_{j}=w_{B}$. From stability in Definition 2 (b), one must have $\pi_{i}+\omega_{j}=\varphi(i, \mu(i) ; \gamma)-w_{A \ell}(\gamma)+w_{B} \geq \varphi(i, j ; \gamma)$. From this inequality, one derives with the help of (6), (7), and $c(\mu(i))=\ell$ that $w_{A \ell}(\gamma) \leq w_{B}+\rho_{\ell}(\gamma)\left[f_{a}^{\prime}(i)-f_{b}^{\prime}(i)\right]$. Taking the limit as $i \rightarrow N_{A}$, one arrives at $w_{A \ell}(\gamma) \leq w_{B}+\rho_{\ell}(\gamma)\left[f_{a}^{\prime}\left(N_{A}\right)-f_{b}^{\prime}\left(N_{A}\right)\right]$.

From Proposition 2 (c), one can find a sequence of firms $i \in\left[N_{A}, N\right)$ such that all $i$ in the sequence are matched to workers $\mu(i) \in J_{B}$ and such that the sequence converges to $N_{A}$. From Proposition 3 , for all those $i$, one has $\pi_{i}=\varphi(i, \mu(i) ; \gamma)-$ $w_{B}$. Consider some worker $j \in J_{A \ell}$ who has a job and so earns $\omega_{j}=w(\mu(j))=$ $w_{A \ell}(\gamma)$. Stability requires $\pi_{i}+\omega_{j}=\varphi(i, \mu(i) ; \gamma)-w_{B}+w_{A \ell}(\gamma) \geq \varphi(i, j ; \gamma)$. Inserting (7), (6), and $c(j)=\ell$, one finds $w_{A \ell}(\gamma) \geq w_{B}+\rho_{\ell}(\gamma)\left[f_{a}^{\prime}(i)-f_{b}^{\prime}(i)\right]$. In the limit for $i \rightarrow N_{A}$, one so has $w_{A \ell}(\gamma) \geq w_{B}+\rho_{\ell}(\gamma)\left[f_{a}^{\prime}\left(N_{A}\right)-f_{b}^{\prime}\left(N_{A}\right)\right]$ which establishes the claim.

(c) A similar argument as in the proof of claim (b) shows that $\varphi(i, \mu(i) ; \gamma)-$ $w_{A h}(\gamma)+w_{A \ell}(\gamma) \geq \varphi(i, j ; \gamma)$, where $i \in\left[0, N_{A h}\right)$ with $\mu(i) \in J_{A h}$ is any firm from a sequence converging to $N_{A h}$, and the alternative worker is $j \in J_{A \ell}$. Also, one arrives at $\varphi(i, \mu(i) ; \gamma)-w_{A \ell}(\gamma)+w_{A h}(\gamma) \geq \varphi(i, j ; \gamma)$, where $i \in\left[N_{A h}, N_{A}\right)$ with $\mu(i) \in J_{A \ell}$ is any firm from a sequence converging to $N_{A h}$, and the alternative worker is $j \in J_{A h}$. The claim is established by inserting expected outputs and taking the limit for $i \rightarrow N_{A h}$ in both inequalities.

Proof of Proposition 7. (a) Consider first a vote between $\gamma_{b \ell}$ and some $\gamma^{\prime}>\gamma_{b \ell}$. From $w_{a \ell}^{\prime}(\gamma)<0$ for all $\gamma \in[0,1]$, the students of type $a \ell$ prefer $\gamma_{b \ell}$ over $\gamma^{\prime}$. This is obviously also true for the students of type $b \ell$. Together, these two groups form a majority from $n_{\ell}=n_{a \ell}+n_{b \ell}>N / 2$.

Alternatively, if some $\gamma^{\prime}$ with $0<\gamma^{\prime}<\gamma_{b \ell}$ is posted against $\gamma_{b \ell}$ observe that from $\operatorname{SOC}(\gamma)>0, \sigma(\gamma)>-1$ is equivalent to $\operatorname{SOC}(\gamma)+\gamma \operatorname{SOC}^{\prime}(\gamma)>0$. From (14) and (16), this inequality is equivalent to $w_{b h}^{\prime}(\gamma)>w_{b \ell}^{\prime}(\gamma)$. Since this holds for all $\gamma^{\prime} \leq \gamma \leq \gamma_{b \ell}$

$$
w_{b h}\left(\gamma_{b \ell}\right)-w_{b h}\left(\gamma^{\prime}\right)=\int_{\gamma^{\prime}}^{\gamma_{b \ell}} w_{b h}^{\prime}(\gamma) d \gamma>\int_{\gamma^{\prime}}^{\gamma_{b \ell}} w_{b \ell}^{\prime}(\gamma) d \gamma=w_{b \ell}\left(\gamma_{b \ell}\right)-w_{b \ell}\left(\gamma^{\prime}\right) \geq 0
$$


Thus, all voters of type $b h$ vote for $\gamma_{b \ell}$, as do obviously those of type $b \ell$. From $n_{b}=n_{b \ell}+n_{b h}>N / 2$, this is a majority.

(b) As in case (a), the voters of type al prefer $\gamma_{a h}$ to any alternative $\gamma^{\prime}>\gamma_{a h}$. From $n_{a h}+n_{a \ell}=n_{a}>N / 2$, in such a vote, $\gamma_{a h}$ obtains a majority of votes.

Consider then a vote between $\gamma^{\prime}<\gamma_{a h}$ and $\gamma_{a h}$. Observing that $\operatorname{GRA}(\gamma)>$ $0, \operatorname{SOC}(\gamma)>0$ and $\operatorname{GRA}^{\prime}(\gamma)<0$, one finds that condition (18) is equivalent to $[\operatorname{GRA}(\gamma)+\operatorname{SOC}(\gamma)]+\gamma\left[\operatorname{GRA}^{\prime}(\gamma)+\operatorname{SOC}^{\prime}(\gamma)\right]>\operatorname{GRA}^{\prime}(\gamma)+\operatorname{SOC}^{\prime}(\gamma)$. From (15) and (16), this is equivalent to $w_{b h}^{\prime}(\gamma)>w_{a h}^{\prime}(\gamma)$. Since this holds for all $\gamma^{\prime} \leq \gamma \leq \gamma_{a h}$, voters of type bh prefer $\gamma_{a h}$ over $\gamma^{\prime}$. From $n_{a h}+n_{b h}=n_{h}>N / 2$, a majority of voters chooses $\gamma_{a h}$ in this pairwise vote.

\section{References}

Autor, D. and D. Scarborough (2008), Does job testing harm minority workers? Evidence from retail establishments, Quarterly Journal of Economics $123,219-277$.

Betts, J. (1998a), The impact of educational standards on the level and distribution of earnings, American Economic Review 88, 266-275.

BJERK, D. (2008), Glass ceilings or sticky floors? Statistical discrimination in a dynamic model of hiring and promotion, Economic Journal 118, 961-982.

Blanden, J. and P. Gregg (2004), Family income and educational attainment: A review of approaches and evidence for Britain, Oxford Review of Economic Policy 20, 245-263.

California Teachers Association (2006): State could develop alternative exit exams, California Educator Magazine Vol. 10, issue 7, April 2006, available online at

http://www.cta.org/media/publications/educator/archives/2006/v10i7.htm

Chan, W., L. HaO, and W. Suen (2007), A signalling theory of grade inflation, International Economic Review 48, 1065-1090. 
Clark, S. and R. Kanbur (2004), Stable partnerships, matching, and local public goods, European Economic Review 48, 905-925.

CoAte, S. and G. Loury (1993), Will affirmative-action policies eliminate negative stereotypes?, American Economic Review 83, 1220-1240.

Cole, H., G. Mailath and A. Postlewaite (1992), Social norms, savings behaviour, and growth, Journal of Political Economy 100, 1092-1125.

Corneo, G. and H. Grüner (2000), Social limits to redistribution, American Economic Review 90, 1491-1507.

Costrell, R. (1994), A simple model of educational standards, American Economic Review 84, 956-971.

Costrell, R. (1997), Can centralized educational standards raise welfare?, Journal of Public Economics 65, 271-293.

Costrell, R. and G. Loury (2004), Distribution of ability and earnings in a hierarchical job assigment model, Journal of Political Economy 112, 13221363.

ERmisch, J. and M. FrAnCESCONI (2001), Family matters: Impacts of family background on educational attainments, Economica 68, 137-156.

Gewerkschaft Erziehung Und Wissenschaft (2006), Ermutigung statt Notenschock, press release, June 14th, 2006, available online at http://www.gew.de/Pressemitteilungen.html

Himmler, O. and R. Schwager (2007), Double standards in educational standards: Are disadvantaged students being graded more leniently?, ZEW Discussion Paper 07-016.

Jürges, H., W. Richter, and K. Schneider (2005), Teacher quality and incentives: Theoretical and empirical effects of standards on teacher quality, Finanzarchiv/Public Finance Analysis 61, 298-326.

Madaus, G. and M. Clarke (2001), The adverse impact of high-stakes testing on minority students: Evidence from one hundred years of test data, in: G. ORFIELD and M. KoRnHABER (eds.), Raising standards or raising barriers? 
Inequality and high-stakes testing in public education, New York: The Century Foundation, 85-106.

Mansfield, H. (2001), Grade inflation: It's time to face the facts, The Chronicle of Higher Education, April 6, 2001, available online at http://chronicle.com/free/v47/i30/30b02401.htm

Norman, P. (2003), Statistical discrimination and efficiency, Review of Economic Studies 70, 615-627.

Plug, E. and W. Vijverberg (2003), Schooling, family background, and adoption: Is it nature or is it nurture?, Journal of Political Economy 111, 611641.

Roth, A. and M. Sotomayor (1990), Two-sided matching: A study in gametheoretic modeling and analysis, Cambridge University Press.

SPIEGEL ONLINE (2007), Inflation der Kuschelnoten, May 14th, 2007, available online at http://www.spiegel.de/spiegel/0,1518,482849,00.html

Sattinger, M. (1993), Assignment models of the distribution of earnings, Journal of Economic Literature 31, 831-880.

Teulings, C. (1995), The wage distribution in a model of the assignment of skills to jobs, Journal of Political Economy 103, 280-315.

Wössmann, L. (2008), How equal are educational opportunities? Family background and student achievement in Europe and the United States, Zeitschrift für Betriebswirtschaft/Journal of Business Economics, special issue 1/2008, 45-70. 